\title{
Restoring Natural Hip Movements with Large Head (Ceramic on Ceramic) Total Hip Replacement: Experience of Our 150 Patients over 6 Years
}

\author{
Sanjay Agarwala*, Mayank Vijayvargiya, Sameer Chaudhari \\ Department of Orthopedics, P.D. Hinduja National Hospital, Mumbai, India \\ Email: *drsa2011@gmail.com
}

How to cite this paper: Agarwala, S., Vijayvargiya, M. and Chaudhari, S. (2017) Restoring Natural Hip Movements with Large Head (Ceramic on Ceramic) Total Hip Replacement: Experience of Our 150 Patients over 6 Years. Open Journal of Orthopedics, 7, 414-427.

https://doi.org/10.4236/ojo.2017.712044

Received: November 7, 2017

Accepted: December 2, 2017

Published: December 5, 2017

Copyright $\odot 2017$ by authors and Scientific Research Publishing Inc. This work is licensed under the Creative Commons Attribution International License (CC BY 4.0).

http://creativecommons.org/licenses/by/4.0/

\section{Open Access}

\begin{abstract}
Background: Asian cultures require floor-seated positions demanding a high range of motion (ROM). Ceramic-On-Ceramic (COC) interface allowed the use of larger head with reduced wear debris generation and adverse tissue reactions. This study was conducted to analyze 6-year clinical-radiological outcome with large head fourth generation DeltaMotion ${ }^{\circledR}$ ceramic-on-ceramic (COC) hip articulation, with special emphasis on postoperative ROM, ability to sit cross-legged, stability, hip noise and revision surgery. Material and Methods: 150 consecutive hips were operated for primary cementless Total Hip Replacement (THR) using DeltaMotion ${ }^{\circledR}$ at a tertiary care center in Mumbai, India, between January 2010 and January 2015. Clinico-radiological outcome was assessed using the Harris Hip Score (HHS) and radiographs at 6 weeks, 6 months, and annually thereafter. Results: 108 (74.5\%) patients were males and 37 (25.5\%) were females with an average age of 50.87 years. Mean follow-up was 54 months (range: 37 - 86 months). The mean ROM was $120^{\circ}$ in flexion, $10^{\circ}$ in extension, $30^{\circ}$ in adduction, $45^{\circ}$ in abduction, $25^{\circ}$ in internal rotation and $25^{\circ}$ in external rotation. The mean HHS showed a statistically significant improvement of $64.5 \%$ (from $54.66 \pm 6.42$ pre-operatively to 89.95 \pm 4.32 post operatively) (p-value: 0.001 ). $92 \%$ of patients were able to sit in squatting position and $92 \%$ were able to sit cross-legged on the floor at last follow-up. 0.7\% joints (1 hip) had squeaking. Considering no revision surgery as the end point, 6-year prosthesis survivorship was $100 \%$. Complications (superficial infection) occurred in three hips (2\%). All patients reported to be satisfied with their outcome after surgery. Conclusion: We infer that DeltaMotion large head COC bearing allows scope for using larger head size in relatively smaller Indian hips due to factory fitted ceramic lining. At 6-year
\end{abstract}


follow-up, high activity level was observed with excellent clinical-radiological outcomes and component longevity in relatively young Indian population.

\section{Keywords}

Ceramic-on-Ceramic, Total Hip Arthroplasty, Squeaking, Prosthesis Survivorship, Harris Hip Score

\section{Introduction}

Total Hip Replacement (THR) has stood the test of time for elderly patients, but as the indications for THR expanded to include younger patients with a more active lifestyle, "implant survivorship" emerged as a concern. Head size and biocompatibility of the bearing surfaces are two critical factors responsible for the clinical success of a hip implant, other than the fixation to the bone. The challenge in young patients undergoing THR is the longevity of the implant and ROM which is expected to be as physiologically normal as others of their age.

Conventional joint replacement implants are better suited for Western lifestyles and needs [1]. Asian patients expect a higher range of motion post THR considering their routine cultural practices which involve floor seated positions (cross-legged sitting, squatting and kneeling). Surgeons face high expectations from patients who want to resume these demanding activities with a better quality of life than before surgery. In a study conducted by Prakash V et al. [2], toileting (78\%), bathing (68\%), eating (68\%), praying (54\%) and work (51\%) were the activities for which squatting and sitting on the floor were rated as very important by the Indian population. Identifying such activities valued by patients' is essential to optimize rehabilitation outcomes after THR. This requires treating an orthopedic surgeon to determine an implant type which fulfills the cultural needs of local population.

Many studies have shown that large head MOM THA has better postoperative activity level compared to conventional THA due to increased ROM [3] [4] [5]. Hence, large head MOM Total Hip Arthroplasty (THA) including hip resurfacing became popular in Asia [6]. However, many studies then showed increased concerns with MOM THA leading to metallosis, aseptic loosening, and ALVAL (Aseptic Lymphocytic Vasculitis Associated Lesions) [7] [8]. This led to a need for a system which could incorporate the benefits of large head leading to better ROM and emanate the disadvantages of metal on metal interface.

COC bearing for THA was first introduced by Boutin in France during the 1970s [9]. Properties like stable chemical inertia, less aseptic loosening, reliable biocompatibility, high hardness, inert wear debris and a low coefficient of friction made COC couplings popular in recent years [10] [11]. However, potential disadvantages of COC are high cost, the risk of component fracture and squeaking. Early experiences with ceramics had poor results, but it has led to many improvements in the manufacture and design of subsequent implants [12]. Recent 
move towards hard-on-hard ceramic-bearing couplings is due to constant improvements in manufacturing techniques which led to a shift from large head MOM to large head COC, with an aim of providing improved ROM and longevity.

Studies have shown that large head COC THA improved ROM, had lower dislocation rates and better short to mid-term survivorship [13] [14] [15]. However, evidence is still lacking about the outcome of large head COC THA in the Asian population, where squatting and sitting cross-legged is an integral part of daily activities. Therefore, there is a need for a study evaluating the functional outcome in terms of Activities of Daily Living (ADL) performed, and implant survivorship in the Asian population.

This study was conducted to evaluate the results of large head, fourth generation DeltaMotion ceramic on ceramic (COC) hip articulation in terms of postoperative ROM, ability to sit cross-legged, stability, hip noises, complications and need for revision surgery in the Indian patients.

\section{Material and Methods}

We conducted a retrospective analysis of our first 150 consecutive prospectively collected/followed up cases (108 males and 37 females) operated for primary cementless THR with DeltaMotion ${ }^{\circledR}$ Hip System at tertiary care hospital in Mumbai, India between January 2010 and January 2014. All the patients requiring THR for various reasons were offered DeltaMotion hip system without any selection/exclusion criteria during the study period. We have reviewed our first 150 operated cases, although adequate sample size was not defined. Institutional ethics committee approval was taken prior to data analysis. Clinical and radiographic assessments were done at 6 weeks, 6 months, and annually thereafter until the last follow-up.

\subsection{Surgical Technique}

All operations were performed by a single surgeon (SA), using an anterolateral Hardinge approach. The femoral head size was determined as per the size of acetabular component (Table 1). Components used were a. The DeltaMotion Cup which is a titanium alloy shell with a pre-assembled CeramTec BIOLOX ${ }^{\circledR}$ delta ceramic liner (DePuy Synthes). b. Femoral Head: Biolox Delta (DePuy

Table 1. Femoral head size and corresponding acetabular component.

\begin{tabular}{cc}
\hline Femoral head $(\mathrm{mm})$ & Acetabulum $(\mathrm{mm})$ \\
\hline 32 & 42 or 44 \\
36 & 46 or 48 \\
40 & 50 or 52 \\
44 & 54 or 56 \\
48 & $>56$ \\
\hline
\end{tabular}


Synthes) c. Femoral Stem: Corail uncemented (DePuy Synthes) in all the cases.

\subsection{Post-Surgical Rehabilitation}

Patients were made to sit up within 3 hours after surgery. After the effect of spinal anesthesia wore away, patients were made to walk with an aid of walker on the same day of surgery. Hip range of motion exercises was started the next day. Prescribed follow-up visits were at week 1, week 3, week 6, 6 months, 1 year followed by annual follow-up.

\subsection{Clinical Assessment}

Harris Hip Score (HHS) was used for clinical assessment. The score is considered excellent if it is between 90 and 100, good if between 80 and 90, fair if between 70 and 80, and poor if below 70. During the clinical assessment, careful attention was paid to region-specific movements like squatting or sitting crosslegged. Patient Reported Outcome Measures (PROMs) like the ability to squat, sit cross-legged or any squeaking were also noted. HHS and PROMs also tell us the satisfaction of the patient in terms of outcome following THR.

\subsection{Noise Assessment}

Patients were asked binary questions (yes/no) on audible squeaking during hip movements like click, grind, snap etc.

\subsection{Radiological Assessment}

Standard radiographs (anteroposterior view of the pelvis with both hips and both hips frog leg lateral) were taken for all patients immediately postoperatively and at subsequent follow-up visits. Two independent radiographic reviewers (who are not a part of the study) evaluated all study radiographs using IMPAX PACS tools. The recommended acetabular component position for the Delta Motion implant is an inclination of $30^{\circ}$ to $40^{\circ}$ and an anteversion of $15^{\circ}$ to $20^{\circ}$ [16]. Patients were considered to have a radiographic failure if any of the following four criteria were met at any time after surgery: radiolucencies greater than $2 \mathrm{~mm}$ observed in any zone; acetabular cup migration greater than $4 \mathrm{~mm}$; acetabular cup inclination change of more than $4^{\circ}$ when compared with the immediate postoperative angle; or any osteolysis observed around any of the implanted components. A cup was defined as stable if there was no measured migration or inclination change as described.

\subsection{Adverse Events}

Any adverse events were recorded at all study intervals and interim visits. Complications were separated into intra-operative and postoperative events. Any hip that underwent a reoperation where-in any of the device components (i.e. femoral head or stem, acetabular liner, or shell) was removed at any time was considered a revision and a survivorship failure. 


\subsection{Statistical Analysis}

SAS statistical software, Version 10 (SAS Institute Inc.) was used for all analyses. For descriptive analysis, continuous variables were summarized by using summary statistics i.e. a number of observations, mean and standard deviation with ranges. Categorical values were summarized by using frequencies and percentages. The changes in average Harris Hip score were estimated by student t-test. All p-values were reported based on two-sided significance test and all the statistical tests were interpreted at $5 \%$ level of significance level.

\section{Results}

Out of the first 150 cases operated with DeltaMotion ceramic-on-ceramic (COC) hip articulation, 147 cases were available for analysis and 3 cases lost to followup. Mean duration of follow up was 54 months (range 37 - 86 months). There were 108 male patients and 37 female patients. Avascular Necrosis of Hip (AVN) (60\%) was the most common indication for THR followed by fracture of neck/head of femur (14.7\%) (Table 2). Patient demographics are mentioned in Table 2 .

\subsection{Clinical Assessment}

The median femoral head size was $40 \mathrm{~mm}$ (minimum-36 $\mathrm{mm}$; maximum-48 $\mathrm{mm}$ ) and that of the acetabulum was $52 \mathrm{~mm}$ (minimum-46; maximum-64). The mean range of movement was $120^{\circ}$ in flexion, $10^{\circ}$ in extension, $30^{\circ}$ in adduction, $45^{\circ}$ in abduction, $25^{\circ}$ in internal rotation and $25^{\circ}$ in external rotation.

Table 2. Patient Demographics.

\begin{tabular}{|c|c|}
\hline Total number of hips & 150 \\
\hline Total number of patients & 145 \\
\hline Males (\%) & $108(74.5 \%)$ \\
\hline Females (\%) & $37(25.5 \%)$ \\
\hline \multirow{2}{*}{ Profile of side among study cases } & 52.7\% Right side \\
\hline & 47.3\% Left side \\
\hline Mean age (years, SD) & 50.87 years \\
\hline Mean BMI $\left(\mathrm{Kg} / \mathrm{m}^{2}, \mathrm{SD}\right)$ & $27.22 \mathrm{~kg} / \mathrm{m}^{2}$ \\
\hline Diagnosis & Number of hips \\
\hline AVN & $90(60 \%)$ \\
\hline Fracture neck and head femur & $22(14.7 \%)$ \\
\hline Osteoarthritis & $14(9.3 \%)$ \\
\hline Post-traumatic arthritis & $10(6.7 \%)$ \\
\hline Ankylosing spondylitis & $6(4 \%)$ \\
\hline Rheumatoid arthritis & $5(3.3 \%)$ \\
\hline Others & $3(2 \%)$ \\
\hline Mean follow up duration (months) & 54 months (range 37 - 86 months) \\
\hline
\end{tabular}




\subsection{Harris Hip Score}

The mean HHS improved from $54.66 \pm 6.42$ pre-operatively to $89.95 \pm 4.32$ postoperatively i.e. difference of $64.5 \%$ from baseline, which was statistically highly significant (p-value: 0.001 ) (Figure 1). $92 \%$ of patients were able to sit in squatting position and $92 \%$ were able to sit cross-legged without any difficulty at their last follow up. Clinical and radiographs of a representative patient are shown in Figures 2-5 showing good results.

\subsection{Radiographic Assessment}

No acetabular cup/femoral stem loosening, migration or radiolucency was seen in any case at a mean follow-up of 54 months.

\subsection{Noise Assessment}

A single case (0.7\%) had a "squeak" and the remaining hips were silent. No other noise types were reported or observed during clinical assessment with various

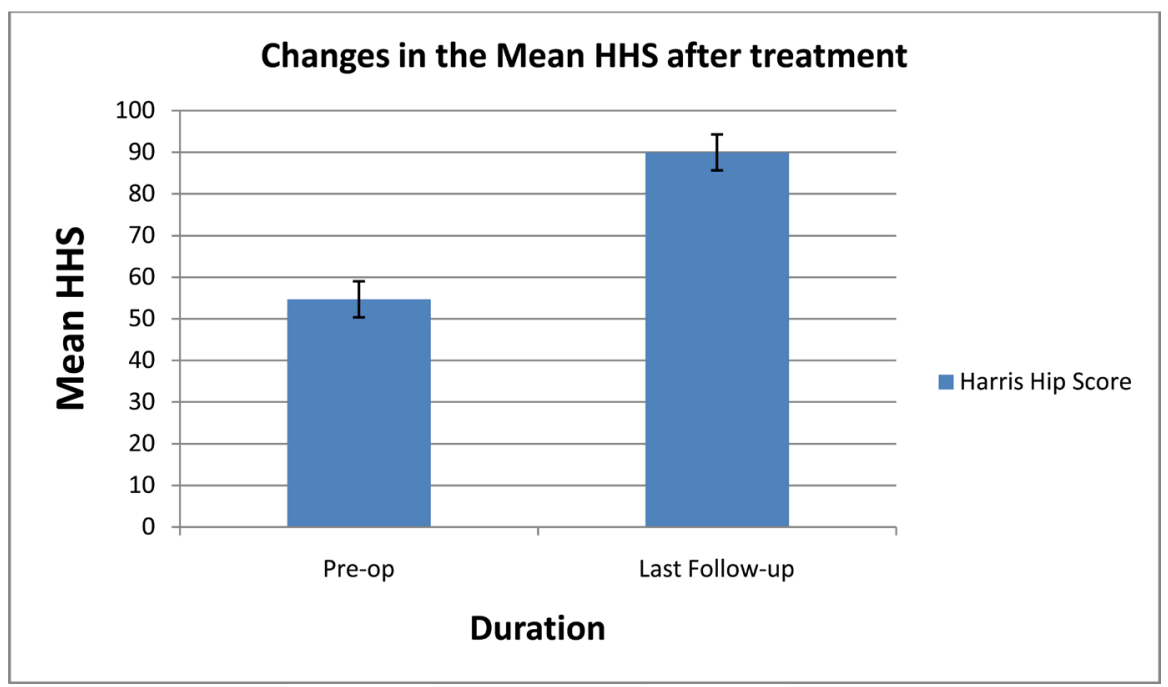

Figure 1. Bar diagram showing improvement in Harris Hip Score at last follow-up as compared to pre-surgery levels.

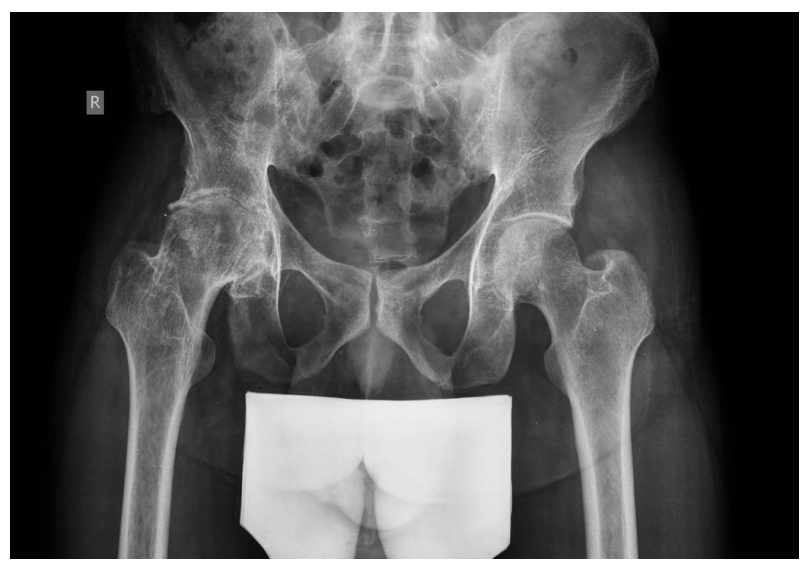

Figure 2. X ray AP pelvis of representative case-pre-operative. 


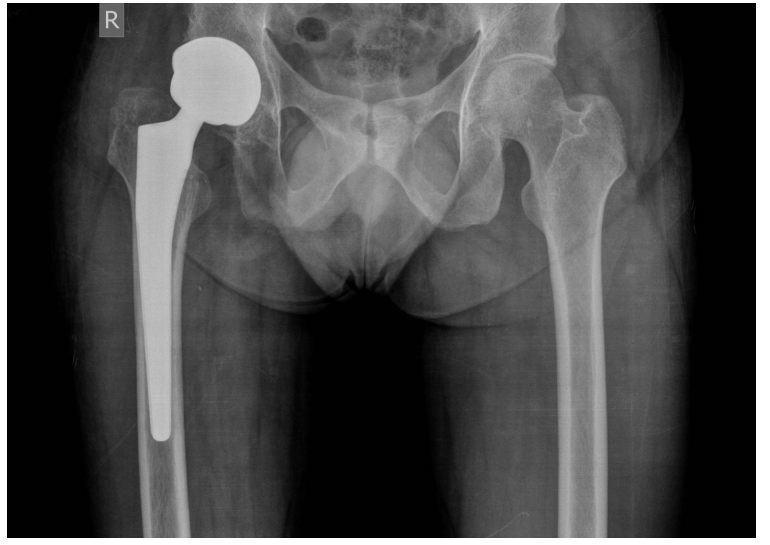

Figure 3. Radiograph AP pelvis at 1 month post surgery with DeltaMotion prosthesis.

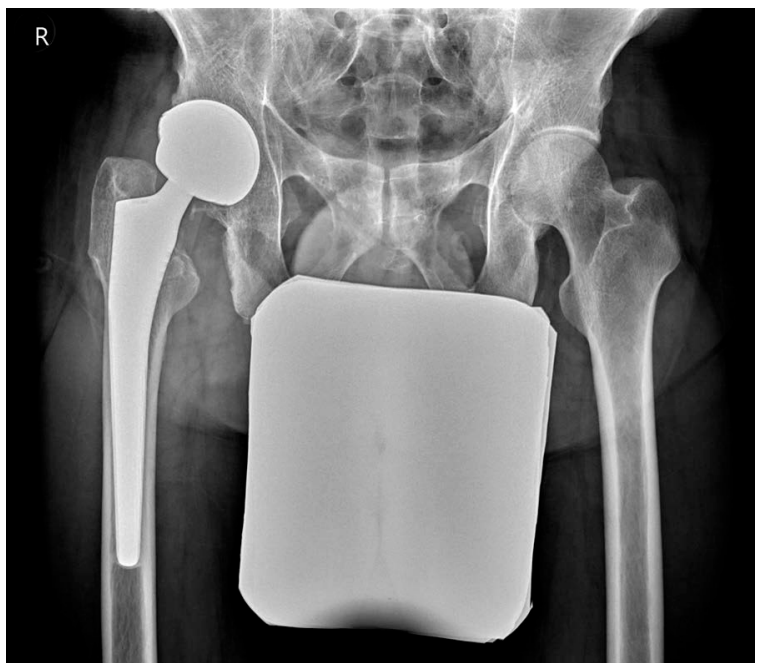

Figure 4. Radiograph AP view pelvis at 5 year post surgery with DeltaMotion prosthesis.
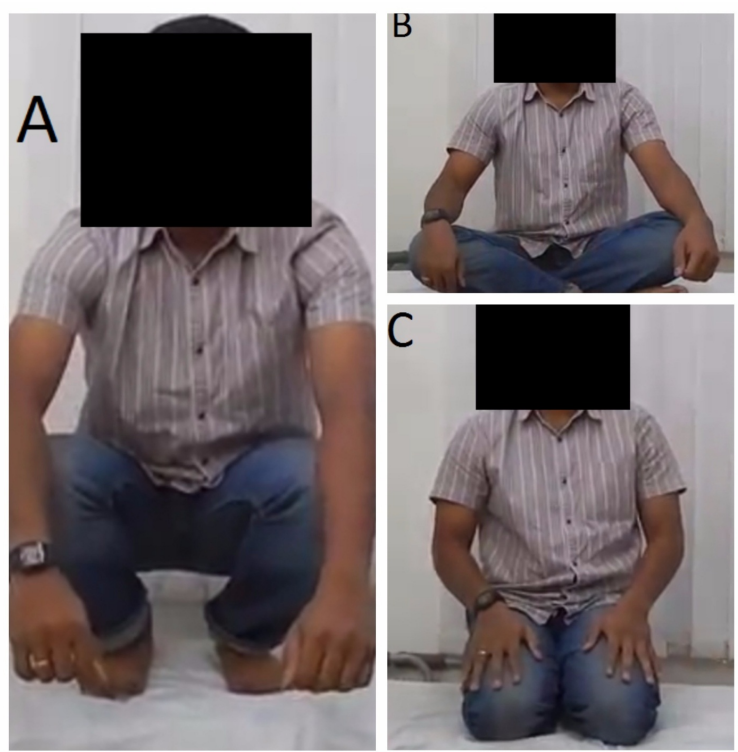

Figure 5. (a) Photograph of a representative study patient in squatting position, (b) in cross-legged sitting position, (c) in kneeling position. 
hip movements. The singular incident of joint squeak was managed by reassurance and no further management was required. No case of ceramic fracture was reported.

\subsection{Safety Assessment}

There were no revision surgeries. Other than one patient who complained of squeaking, there were 3 cases of superficial surgical site infection. All 3 cases of superficial infection did not require any surgical intervention and were healed eventually with no long-term complications. No peri-prosthetic fractures were reported. All patients reported being satisfied with their outcome after surgery.

\section{Discussion}

\subsection{Status of COC Hip Articulation System}

Asian patients expect a near normal pre-surgery functional status post-THA. Their concerns with conventional THA are the restriction of activities of daily living like squatting, kneeling and sitting cross-legged on the floor. MOM Large head THA helped in a large way to resolve their issues and became popular in the Asian subcontinent [6]. However, various studies then reported increased concerns with MOM large head THA, which led way to the large head COC THA, which included the advantages of the large head and lowered the complications associated with MOM THA. Ceramic particles induce relatively less macrophage reaction and decreased cytokine secretion compared to particles of high-density polyethylene [17]. As a result of the improved survival of uncemented THR components using COC bearings, their use has increased despite the higher costs [18] (Table 3).

\subsection{Advantages of Larger Femoral Head}

A strong relationship between larger femoral heads and lower dislocation rates is well established [19] [20]. Amstutz et al. [21] reported an improvement in ROM with $32 \mathrm{~mm}$ diameter head compared to $22 \mathrm{~mm}$ diameter head due to greater head: neck ratio (1.98 vs. 1.74). Elkins et al. [22] reported that appreciable

Table 3. Factors affecting femoral head size.

\begin{tabular}{|c|c|}
\hline \multicolumn{2}{|c|}{ Factors determining ideal head size } \\
\hline Factors favoring large diameter head & Factors limiting head diameter \\
\hline $\begin{array}{l}\text { - Lower dislocation rates } \\
\text { - Improved stability } \\
\text { - Increased head-neck ratio leads to } \\
\text { greater ROM } \\
\text { - Impingement-free ROM } \\
\text { - Near "anatomic" head size } \\
\text { - COC large heads have less stripe wear } \\
\text { - COC heads have lower risk of femoral } \\
\text { head fracture }\end{array}$ & $\begin{array}{l}\text { - Patient anatomy } \\
\text { - Bearing material } \\
\text { - Increased serum ions in MOM hip arthoplasty } \\
\text { - Recent concerns of adverse local tissue } \\
\text { reactions (ALTR) and aseptic lymphocytic } \\
\text { vasculitis-associated lesions (ALVAL) with } \\
\text { MOM hip } \\
\text { - Psoas impingement (noted with MOM) }\end{array}$ \\
\hline
\end{tabular}


improvement in stability occurred when femoral head size was increased from $32 \mathrm{~mm}$ to $36 \mathrm{~mm}$. However, there were not much further gains in stability with the increased head size beyond $36 \mathrm{~mm}$. This was proved by an observation that $10 \%$ improvement in stability occurred when femoral head size was increased from $32 \mathrm{~mm}$ to $36 \mathrm{~mm}$ while only $4.7 \%$ improvement occurred when femoral head size was increased from $40 \mathrm{~mm}$ to $48 \mathrm{~mm}$. Rodriguez and co-workers have also reported that stability advantages of increasing diameter beyond $38 \mathrm{~mm}$ are not clear [23].

Indian patients have a smaller acetabulum, more so for Indian female patients. Singh et al studied 100 Indian hips and reported a mean cup size of $48.9 \pm 3.67$ $\mathrm{mm}$ (34 - 58), which is significantly smaller than European population [24]. Thus in conventional THA systems, this will, in turn, reduce the femur head size to either 28 or $32 \mathrm{~mm}$. Conventional hips always have a small head due to technical and manufacturing limitations. But since the advent of DeltaMotion, it was possible to use larger head size due to factory fitted ceramic lining, unlike previous generation ceramic hips where the liner had to be fitted during surgery. This scope for using larger heads contributed in a big way in increasing the stability of the hip joint. In current study minimum head size used was $36 \mathrm{~mm}$ for an acetabulum of size as small as $46 \mathrm{~mm}$.

\subsection{Younger Age Group of THR Patients}

Few recent studies have included younger THR patients. Evangelista PJ et al. [25] reported clinical results of COC THA in patients with an average age of 31.03 years with a diagnosis of osteonecrosis. Also, data from Australian National Joint Registry estimated that $13 \%$ of the patients undergoing THA are younger than 55 years [26]. Our study also had patients with a relatively younger average age of 50.87 years. $26.2 \%$ patients were females, thus throwing light on the use of COC bearings on female population, especially with childbearing potential, where MOM implants pose a concern of metallosis.

\subsection{Comparing Hip Harris Score Improvement}

Wan G et al. [27] reported a statistically significant improvement in HHS in a 9.5-year long follow-up, in a retrospective analysis of 68 patients with thirdgeneration COC total hip arthroplasty. Schroder D et al. [28] evaluated 436 alumina-on-alumina, cementless, primary THAs prospectively in 2011. The mean HHS was increased from 51.9 preoperatively to 94.4 at 3-year follow-up. Our study corroborates similar findings and reported mean HHS improvement from 54.66 points preoperatively to 89.95 points at a final follow-up after 6 years.

\subsection{Comparing Prosthetic Survivorship}

Studies with early generation ceramic bearings yielded $68 \%$ to $84 \%$ mean survivorship at 20 years follow-up [29]. A recent systematic review of COC THRs confirmed excellent survivorship of the modern implants of up to $97 \%$ at 10 
years [30]. Gallo et al. [31] reported a 10-year revision-free interval of $92 \%$ to $99 \%$. Our study reported a $100 \%$ prosthetic survivorship and no iterative surgery over 6 years, which corroborates the results of Jeffers et al. [30].

\subsection{Squeaking}

An Australian study reported $0.7 \%$ squeaking in COC hips, and the authors observed that the squeaking phenomena occurred in patients who were taller, heavier, and younger [32]. Other studies have reported squeaking rates between $0.3 \%$ and $24.6 \%$ [33] [34] [35]. Current study also reported similar squeaking rates as the Australian registry [26] (0.7\%).

\subsection{Radiological Findings}

In the current study, post-operative radiography showed no radiolucencies. No incidences of the cup or stem migration, lucency zone, or acetabular migration were observed. All the hips had acetabulum in the safe zone, and there was no squeaking in relation to the inclination of the cup, which is usually the most common complaint observed with COC implant.

\subsection{ROM}

The difference between the technical (theoretically possible) ROM and the true (clinical) ROM reflects the actual effect of increasing the head size on the overall ROM achieved [36]. This "true" ROM realized by the patient is heavily influenced by the orientation of the components, the muscular and soft-tissue condition. In this study, clinical assessment of ROM was done. 92\% of patients were able to sit in squatting position and $92 \%$ crossed their legs without difficulty.

This study reported $120^{\circ}$ of mean range of movement in flexion, $10^{\circ}$ in extension, $30^{\circ}$ in adduction, $45^{\circ}$ in abduction, $25^{\circ}$ in an internal rotation and $25^{\circ}$ in external rotation in patients after surgery. The mean global ROM of $255^{\circ}$ in this study is in concordance with previously reported 2-year analysis of Agarwala et al. [6], where reported ROM for COC implant was $253.9^{\circ}$.

\subsection{Ceramic Fractures}

Ceramic fractures of a contemporary COC articulation of another design reported in a recent study were 1\% [17]. Following improvements in manufacturing technology, the fracture rate has reduced from approximately 1 in 2000 to 1 in 10,000 implants though ceramic fracture is still a concern [37] [38]. Our study reported no evidence of ceramic fractures which is an advantage of DeltaMotion.

There are a few limitation of this study. This study presents the mid-term results of DeltaMotion THR, but a longer follow-up will aid more to the literature about the outcome of this system.

\section{Conclusion}

There have been numerous advances in bearing surface technology and the ideal 
couple is yet to be realized. The results of this analysis indicate that primary THA patients treated with large head COC bearings exhibit a lower risk of dislocation, complications or revision surgery. Furthermore, high ROM activities in Asian culture like sitting cross-legged, squatting and kneeling could be performed by patients with ease. With improved tribology and increased longevity of COC bearings, we are on our way to achieving an optimized, perfectly-implanted and well-osseointegrated implant, with a possibility of lasting lifetime. Further multicenter RCTs with large samples and more than 10 years follow-up are warranted. We conclude that at 6-year follow-up, THA with DeltaMotion large head COC bearings affords high activity level with excellent clinical outcomes and component longevity in relatively young primary THA patients, thereby successfully meeting the high ROM demands of Asian cultural set-up.

\section{References}

[1] Mulholland, S.J. and Wyss, U.P. (2001) Activities of Daily Living in Non Western Cultures: Range of Motion Requirements for Hip and Knee Joint Implants. International Journal of Rehabilitation Research, 24, 191-198. https://doi.org/10.1097/00004356-200109000-00004

[2] Prakash, V.R., Patel, S., Hariohm, K.S., Soni, V. and Alagumoorthi, G. (2016) Importance of Squatting and Sitting on the Floor: Perspectives and Priorities of Rural Indian Patients with Stroke. Topics in Stroke Rehabilitation, 23, 240-244. https://doi.org/10.1080/10749357.2016.1151693

[3] Baker, R.P., Pollard, T.C., Eastaugh-Waring, S.J. and Bannister, G.C. (2011) A Medium-Term Comparison of Hybrid Hip Replacement and Birmingham Hip Resurfacing in Active Young Patients. The Journal of Bone \& Joint Surgery, British, 93B, 158-163. https://doi.org/10.1302/0301-620X.93B2.25625

[4] Mont, M.A., Marker, D.R., Smith, J.M., Ulrich, S.D. and McGrath, M.S. (2009) Resurfacing Is Comparable to Total Hip Arthroplasty at Short-Term Follow-Up. Clinical Orthopaedics and Related Research, 467, 66-71.

https://doi.org/10.1007/s11999-008-0465-3

[5] Lavigne, M., Therrien, M., Nantel, J., Roy, A., Prince, F. and Vendittoli, P.A. (2010) The John Charnley Award: The Functional Outcome of Hip Resurfacing and Large-Head THA Is the Same: A Randomized, Double-Blind Study. Clinical Orthopaedics and Related Research, 468, 326-336. https://doi.org/10.1007/s11999-009-0938-Z

[6] Agarwala, S., Mohrir, G. and Moonot, P. (2014) Functional Outcome Following a Large Head Total Hip Arthroplasty: A Retrospective Analysis of Mid Term Results. Indian Journal of Orthopaedics, 48, 410-414. https://doi.org/10.4103/0019-5413.136295

[7] Neumann, D.R., Thaler, C., Hitzl, W., Huber, M., Hofstadter, T. and Dorn, U. (2010) Long Term Results of a Contemporary Metal-on-Metal Total Hip Arthroplasty: A 10-Year Follow-Up Study. The Journal of Arthroplasty, 25, 700-708. https://doi.org/10.1016/j.arth.2009.05.018

[8] Langton, D.J., Jameson, S.S., Joyce, T.J., Gandhi, J.N., Sidaginamale, R.P., Mereddy, P.K., Lord, J.K. and Nargol, V.F.A. (2011) Accelerating Failure Rate of the ASR Total Hip Replacement. Journal of Bone and Joint Surgery, British, 93B, 1011-1016.

[9] Boutin, P. (2014) Total Arthroplasty of the Hip by Fritted Alumina Prosthesis. Ex- 
perimental Study and 1st Clinical Applications. Orthopaedics \& Traumatology: Surgery \& Research, 100, 15-21. https://doi.org/10.1016/j.otsr.2013.12.004

[10] Yoon, H.J., Yoo, J.J., Yoon, K.S., Koo, K.H. and Kim, H.J. (2012) Alumina-on-Alumina THA Performed in Patients Younger than 30 Years: A 10-Year Minimum Follow-Up Study. Clinical Orthopaedics and Related Research, 470, 3530-3536. https://doi.org/10.1007/s11999-012-2493-2

[11] Kang, B.J., Ha, Y.C., Ham, D.W., Hwang, S.C., Lee, Y.K. and Koo, K.H. (2015) Third-Generation Alumina-on-Alumina Total Hip Arthroplasty: 14 to 16-Year Follow-Up Study. The Journal of Arthroplasty, 30, 411-415. https://doi.org/10.1016/j.arth.2014.09.020

[12] Toni, A., Giardina, F., Guerra, G., Sudanese, A., Montalti, M., Stea, S. and Bordini, B. (2017) $3^{\text {rd }}$ Generation Alumina-on-Alumina in Modular Hip Prosthesis: 13 to 18 Years Follow-Up Results. HIP International, 27, 8-13. https://doi.org/10.5301/hipint.5000429

[13] Sugano, N., Takao, M., Sakai, T., Nishii, T., Miki, H. and Ohzono, K. (2012) Eleven-to 14-Year Follow-Up Results of Cementless Total Hip Arthroplasty Using a Third-Generation Alumina Ceramic-on-Ceramic Bearing. The Journal of Arthroplasty, 27, 736-741. https://doi.org/10.1016/j.arth.2011.08.017

[14] Porat, M., Parvizi, J., Sharkey, P.F., Berend, K.R., Lombardi, A.V.Jr. and Barrack, R.L. (2012) Causes of Failure of Ceramic-on-Ceramic and Metal-on-Metal Hip Arthroplasties. Clinical Orthopaedics and Related Research, 470, 382-387. https://doi.org/10.1007/s11999-011-2161-y

[15] Gagala, J., Mazurkiewicz, T. and Dajewski, Z. (2011) Large Diameter Femoral Heads in Primary Alumina/Alumina and XSPE/Alumina Total Hip Arthroplasty. A Follow-Up Study of 50 Hips after Average 40 Months and Review of Literature. Chir Narzadow Ruchu Ortop Pol, 76, 14-20.

[16] McDonnell, S.M., Boyce, G., Baré, J., Young, D. and Shimmin, A.J. (2013) The Incidence of Noise Generation Arising from the Large-Diameter Delta Motion Ceramic Total Hip Bearing. The Bone \& Joint Journal, 95B, 160-165.

https://doi.org/10.1302/0301-620X.95B2.30450

[17] Chan, H.Y., Koo, K.H., Jeong, S.T., Yoo, J.J., Kim, Y.M. and Kim, H.J. (2007) Cementless Alumina-on-Alumina Total Hip Replacement in Patients Younger than 50 Years-A 5-Year Minimum Follow-Up Study. The Journal of Arthroplasty, 22, 184-188. https://doi.org/10.1016/j.arth.2006.02.169

[18] Morshed, S., Bozic, K.J., Ries, M.D., Malchau, H. and Colford, J.M.Jr. (2007) Comparison of Cemented and Uncemented Fixation in Total Hip Replacement: A Meta-Analysis. Acta Orthopaedica, 78, 315-326. https://doi.org/10.1080/17453670710013861

[19] Cuckler, J.M., Moore, K.D., Lombardi, A.V.Jr., McPherson, E. and Emerson, R. (2004) Large versus Small Femoral Heads in Metal-on-Metal Total Hip Arthroplasty. The Journal of Arthroplasty, 19, 41-44. https://doi.org/10.1016/j.arth.2004.09.006

[20] Hummel, M.T., Malkani, A.L., Yakkanti, M.R. and Baker, D.L. (2009) Decreased Dislocation after Revision Total Hip Arthroplasty Using Larger Femoral Head Size and Posterior Capsular Repair. The Journal of Arthroplasty, 24, 73-76. https://doi.org/10.1016/j.arth.2009.04.026

[21] Amstutz, H.C., Lodwig, R.M., Schurman, D.J. and Hodgson, A.G. (1975) Range of Motion Studies for Total Hip Replacements. A Comparative Study with a New Experimental Apparatus. Clinical Orthopaedics and Related Research, 111, 124-130. https://doi.org/10.1097/00003086-197509000-00016 
[22] Elkins, J.M., Callaghan, J.J. and Brown, T.D. (2014) Stability and Trunnion Wear Potential in Large-Diameter Metal-on-Metal Total Hips: A Finite Element Analysis. Clinical Orthopaedics and Related Research, 472, 529-542. https://doi.org/10.1007/s11999-013-3244-8

[23] Rodriguez, J.A. and Rathod, P.A. (2012) Large Diameter Heads. Bone \& Joint Journal, 94, 52-54. https://doi.org/10.1302/0301-620X.94B11.30508

[24] Singh, S., Kumar, S., Rohilla, S. and Maini, L. (2014) Functional Anthropometric Measurements of Indian Pelvis. Journal of Clinical Orthopaedics and Trauma, 5, 79-83. https://doi.org/10.1016/j.jcot.2014.05.001

[25] Evangelista, P.J., Kamath, A.F., Aversano, F.J., Silvestre, J., Lee, G.C. and Nelson, C.L. (2015) Ceramic-Ceramic Hip Arthroplasty for Osteonecrosis: Average 5-Year Follow-up in Patients Less than 50 Years of Age. Bulletin of the Hospital for Joint Disease, 73, 42-45.

[26] Australian Orthopaedic Association (2013) National Joint Replacement Registry. Annual Report. AOA, Adelaide.

[27] Wan, G., Sun, J., Zha, G., Zhao, X., Wang, T., You, Z., et al. (2015) Mid- and Long-Term Effectiveness of Third-Generation Ceramic-on-Ceramic Total Hip Arthroplasty in Younger Patients. Chinese Journal of Reparative and Reconstructive Surgery, 29, 1057-1061.

[28] Schroder, D., Bornstein, L., Bostrom, M.P., Nestor, B.J., Padgett, D.E. and Westrich, G.H. (2011) Ceramic-on-Ceramic Total Hip Arthroplasty: Incidence of Instability and Noise. Clinical Orthopaedics and Related Research, 469, 437-442.

https://doi.org/10.1007/s11999-010-1574-3

[29] Galloa, J., Goodmanb, S.B., Lostaka, J. and Janout, M. (2012) Advantages and Disadvantages of Ceramic on Ceramic Total Hip Arthroplasty: A Review. Biomedical Papers of the Medical Faculty of the University Palacky, Olomouc, Czechoslovakia, 156, 204-212. https://doi.org/10.5507/bp.2012.063

[30] Jeffers, J.R.T. and Walter, W.L. (2012) Ceramic-on-Ceramic Bearings in Hip Arthroplasty: State of the Art and the Future. The Journal of Bone and Joint Surgery, 94, 735-745. https://doi.org/10.1302/0301-620X.94B6.28801

[31] Gallo, J., et al. (2012) Advantages and Disadvantages of Ceramic on Ceramic Total Hip Arthroplasty: A Review. Biomedical Papers of the Medical Faculty of the University Palacky, Olomouc, Czechoslovakia, 156, 204-212. https://doi.org/10.5507/bp.2012.063

[32] Walter, W.L., O’toole, G.C., Walter, W.K., Ellis, A. and Zicat, B.A. (2007) Squeaking in Ceramic-on-Ceramic Hips: The Importance of Acetabular Component Orientation. The Journal of Arthroplasty, 22, 496-503. https://doi.org/10.1016/j.arth.2006.06.018

[33] Owen, D., Russell, N., Chia, A. and Thomas, M. (2014) The Natural History of Ceramic-on-Ceramic Prosthetic Hip Squeak and Its Impact on Patients. European Journal of Orthopaedic Surgery \& Traumatology, 24, 57-61. https://doi.org/10.1007/s00590-012-1142-5

[34] Lusty, P.J., Tai, C.C., Sew-Hoy, R.P., Walter, W.L., Walter, W.K. and Zicat, B.A. (2007) Third-Generation Alumina-on-Alumina Ceramic Bearings in Cementless Total Hip Arthroplasty. The Journal of Bone and Joint Surgery, 89, 2676-2683. https://doi.org/10.2106/JBJS.F.01466

[35] Mai, K., Verioti, C., Ezzet, K.A., Copp, S.N., Walker, R.H. and Colwell, C.W. (2010) Incidence of "Squeaking" after Ceramic-on-Ceramic Total Hip Arthroplasty. Clinical Orthopaedics and Related Research, 468, 413-417. 
https://doi.org/10.1007/s11999-009-1083-4

[36] Spears, I.R., Pfleiderer, M., Schneider, E., Hille, E., Bergmann, G. and Morlock, M.M. (2000) Interfacial Conditions between a Press-Fit Acetabular Cup and Bone during Daily Activities: Implications for Achieving Bone In-Growth. Journal of Biomechanics, 33, 1471-1477. https://doi.org/10.1016/S0021-9290(00)00096-8

[37] Yoo, J.J., Kim, Y.M., Yoon, K.S., Koo, K.H., Kim, J.W., Nam, K.W. and Kim, H.J. (2006) Contemporary Alumina on Alumina Total Hip Replacement. Journal of Biomedical Materials Research Part B: Applied Biomaterials, 78B, 70-75. https://doi.org/10.1002/jbm.b.30457

[38] Baek, S.H. and Kim, S.Y. (2008) Cementless Total Hip Replacement with Alumina Bearings in Patients Younger than Fifty with Femoral Head Osteonecrosis. The Journal of Bone and Joint Surgery, 90, 1314-1320.

https://doi.org/10.2106/JBJS.G.00755 